\title{
CRECIMIENTO Y CONSOLIDACIÓN DE LAS PRINCIPALES AGLOMERACIONES URBANAS ESPAÑOLAS
}

\author{
José Ma . Serrano Martínez \\ Departamento de Geografía \\ Universidad de Murcia
}

\section{RESUMEN}

España es un país bastante urbanizado, con una tasa cercana al 80\%. Las mayores aglomeraciones urbanas (con efectivos humanos en torno a medio millón de habitantes, como umbral mínimo) son 17; en ellas reside casi la mitad de toda su población. Su transformación en la segunda mitad del siglo XX ha sido constante, pero con periodos temporales de incremento e intensidades variadas. Durante los últimos años su ritmo de aumento es fuerte; entre 2001 y 2006 ha crecido un 9,30\%. Se analizan estos procesos de ascenso de la población, sus causas y consecuencias. Junto a ese aumento demográfico se estudian también los profundos cambios estructurales internos que están produciéndose en ellas. Su distribución territorial conforma una red básica imprescindible para entender el funcionamiento del conjunto del sistema urbano nacional. Se aportan, al mismo tiempo, unas consideraciones finales acerca de los principales problemas, ventajas e inconvenientes, que todo ello significa, tanto para las aglomeraciones urbanas en sí mismas, como para la organización territorial del conjunto español.

Palabras clave: aglomeraciones urbanas, crecimiento de la población, organización del territorio, red y sistema urbano.

\begin{abstract}
Spain is a very urbanized country, near to $80 \%$. The biggest urban areas (with a population surrounding or with more than half million of inhabitants) they are 17; in them it resides almost half of the whole Spanish population. Its configuration along the second half of the XX century has continued temporary periods of constant increment, but with varied intensities. During the last years the rhythm of its population's increase is strong; between 2001 and 2006, 9,30\% has grown. These processes of the population's increase, their causes and consequences are analyzed. Next to that demographic increment it is also studied the deep internal structural changes that are taking place in them. Their territorial distribution constitutes an important network to understand the operation of the Spanish urban system. They are contributed, at the same time, some final considerations about the
\end{abstract}


main problems, advantages and inconveniences that everything means it, so much for the urban areas in themselves, as the territorial organization of the Spain.

Key words: urban areas, population's growth, territorial management, urban network and urban system.

\section{Acotaciones preliminares, terminológicas y planteamiento}

Por primera vez en toda su historia más de la mitad de la población mundial reside en ciudades. La trascendencia derivada de tal realidad es muy destacada. Todo apunta a que esta tendencia de expansión urbana se afianzará al paso de los años, aunque de manera dis$\operatorname{par}^{1}$. De ahí se derivan consecuencias plurales de diferente naturaleza. Una cuestión inicial, que surge al ocuparse de estos asuntos, se refiere al propio concepto de lo urbano. Cada vez resulta más difícil delimitar la ciudad, dilucidar dónde comienza y acaba. Las nuevas morfologías urbanas aportan una variedad extensa de formas, con situaciones plurales, que no pueden ni deben dejarse de lado. Frente a la ciudad compacta tradicional es frecuente (el caso español ofrece una transformación reciente palpable) encontrar nuevas formas de hábitat, donde lo urbano adquiere numerosas maneras de mostrarse (Ponce, 2006). El territorio urbanizado ofrece, pues, una creciente complejidad.

Tal realidad, aparte de que abre un fecundo campo de investigación conceptual y teorético de gran interés, representa un problema inmediato para cualquiera ocupado en analizar alguna de las plurales cuestiones relacionas con las entidades urbanas. Se necesita disponer de una terminología lo más precisa posible, que evite confusiones, ayude en los procesos de investigación y contribuya a desbrozar este complejo campo de los espacios urbanos. Es fácil convenir la enorme trascendencia que ello representa para el propio avance científico en cualquier disciplina (Bunge, 1983). La necesidad al estudiar estos temas y el deseo de evitar equivocaciones obliga a aclarar y justificar el término genérico utilizado, el de aglomeraciones urbanas ${ }^{2}$. Sin duda su alcance es impreciso, compromete poco. Pero, precisamente por ello, es capaz de englobar realidades muy dispares, modelos de organización urbana y territorial diferentes, como sucede con la propia casuística española, aquí abordada.

Las AAUU están marcadas por dos denominadores comunes: formales y funcionales, entendidos ambos en su sentido extenso. Los primeros, formales, suelen agrupar una serie de entidades urbanas, con sus correspondientes núcleos compactos, además de otras formas de poblamiento complementarias. Es frecuente que entre ellos exista una cierta jerarquía urbana, marcada tanto por sus volúmenes demográficos dispares, como por su roles tradicionales, que el paso de la historia ha ido sedimentando. Junto a esos núcleos urbanos netos, fácilmente perceptibles, se añaden, superponen y agregan, en sus alrededores, proximidades y cercanías, otras formas de expansión y crecimiento urbanas que siguen tipologías de asentamientos plurales y disímiles. Éstas alcanzan y muestran en los últimos lustros un inusual dinamismo en su expansión. El policentrismo urbano, unido a ese desarrollo tentacular y desparramado de sus periferias, conduce al final a una clara complejidad del espacio urbanizado. Los últimos resultados percibidos no dejan de ser formas híbridas, en

1 A menudo se exponen sobre esto prospecciones alarmantes. Esto se hace tanto en lo referente a la dinámica global de la población, como a la proporción de la misma localizada en las áreas urbanas. Una postura bastante equilibrada al respecto corresponde a las Naciones Unidas, me refiero a su publicación reciente (2006).

2 En adelante, y para abreviar, se usará el acrónimo AAUU en plural y AU en singular. 
las que, si bien se reconocen los rasgos históricos de las ciudades tradicionales, éstos se mezclan con otros importados, claramente foráneos.

Los segundos, los denominadores funcionales, no son tan fáciles de percibir, aunque no por ello su realidad es menos evidente. De un lado, las infraestructuras de transporte que canalizan los desplazamientos de personas y mercancías constituyen una radiografía evidente de las continuas relaciones existentes. Pero, de otro, cada vez más, los flujos inmateriales adquieren mayor importancia, si bien no se advierten visualmente. Incluso es más difícil seguir su rastro. Hoy puede afirmarse con toda rotundidad que los flujos constituyen la lógica espacial dominante (Castells, 1995). Se ha pasado de la dominación del espacio por los lugares, al presente, que lo es, por los flujos. Ahora bien, esta estructura invisible no aparece de forma espontánea ni aleatoria. En buena medida, materialmente se encuentra asentada y gestada desde los centros urbanos tradicionales.

Dado que el ámbito territorial del análisis abarca el conjunto español, al seleccionar las mayores AAUU, dentro de ellas se pueden distinguir ejemplos conspicuos de áreas metropolitanas, con casos singulares de conurbaciones y muestras numerosas de ejemplos suburbanos, periurbanos y rururbanos. Todos es posible englobarlos bajo la denominación genérica de AAUU. No faltan incluso algunos ejemplos representativos de «regiones urbanas» (Hall, 2006).

Los elementos básicos planteados, como puntos de referencia inicial, se resumen en los siguientes términos:

a) La población residente, en lo que se pueden considerar mayores AAUU españolas, alcanza una significación destacada, 21,3 millones de personas, lo cual representa casi la mitad del total de sus efectivos humanos. Tanto la cantidad como su proporción no dejan de crecer al paso de los años. Constituye un indicador claro de su vitalidad y dinamismo. Consiguen esa dimensión y continúan su ascenso con intensidades dispares, motivadas por causas no siempre coincidentes. El análisis de esta evolución temporal permite establecer interesantes comparaciones acerca de la disimilitud y circunstancias que han favorecido su consolidación.

b) Su disparidad de tamaño demográfico, así como los diferentes rasgos inherentes a su morfología y organización interna, muestran una clara heterogeneidad. Ello no impide que todas participen de constantes comunes aunque inducidas por modelos de crecimiento disímiles.

c) Estas AAUU constituyen los nodos básicos de la organización del territorio a la vez que centran las principales actividades productivas. Si bien distan de articular una red mallada equilibrada, puede añadirse que conforman una serie de nodos relativamente proporcionales y ajustados, que jalonan parte del conjunto español, salvo el gran área central, excepción de la AU madrileña.

d) Cara a su devenir cercano se advierte que estas AAUU encierran destacados activos, a la vez que su devenir está acompañado de numerosos riesgos y problemas, en especial si prosigue su ritmo vivo de crecimiento y expansión.

En definitiva, los presupuestos apuntados, muestran dos cosas; de una parte, una realidad general, marcada por el destacado protagonismo de tales AAUU de gran envergadura y significación para el devenir del conjunto de la vida española. De otra, se advierte una pluralidad compleja de situaciones, dentro de ese panorama común mayor. Un enorme y vasto reto para abordar, desde diferentes disciplinas. En este caso, sólo se intenta iniciar un acercamiento desde su interpretación geográfica.

La hipótesis de trabajo propuesta se resume en los siguientes aspectos. 
a) Si se trata de calibrar el fenómeno urbano, de sus mayores entidades, para ello es conveniente contemplar los valores demográficos conjuntos, ampliando el ámbito de los municipios centrales al de sus alrededores e inmediaciones, adonde se traslada su incremento poblacional; pues conforman AAUU de facto. Con independencia de que algunas respondan con mayor precisión a otras estructuras urbanas específicas.

b) Al constatar un aumento demográfico intenso, pero disímil, acentuado en los últimos años y con un dispar repunte reciente, eso plantea numerosas cuestiones. Así, se abre una realidad que está produciendo cambios apreciables en su organización interna; a saber, entre otros: aumento y reajuste de las coronas urbanas, nuevas formas de poblamiento, etc. que originan un escenario complejo.

c) Lo anterior parece conducir hacia un proceso de cierta polarización y un reforzamiento de su peso dentro del sistema urbano español; confirmando, en su caso, la existencia de un nuevo panorama de naturaleza múltiple y complicada forma.

\section{Proceso de crecimiento de las AAUU, una interpretación}

La variable poblacional constituye el eje central de esta investigación. De sobra es sabido que es básica a la hora de calibrar la importancia y dimensión urbanas. En la propia esencia de nuestra disciplina, la geografía, la relación del hombre con su entorno constituye uno de sus asuntos clave. De ahí que todo proceso de análisis urbano que utilice de manera central a los habitantes como criterio de evaluación conlleva una lógica difícil de cuestionar (Marshall, 1989). Por otro lado, los desplazamientos humanos de unos lugares a otros son una constante. En gran medida éstos confirman la existencia de condiciones favorables, de atracción, o en su caso, negativas, de repulsión. Desde ese presupuesto inicial, básico y sin duda incompleto, la dinámica de evolución demográfica constituye un claro síntoma del balance y la evolución de cualquier entidad urbana. Una tendencia al alza suele ser claro síntoma de un ascenso productivo o de una situación con expectativas favorables, o menos negativas que las de otras partes. Balances opuestos apuntan situaciones de naturaleza contraria. Estas afirmaciones no sugieren ninguna apuesta por un rápido crecimiento urbano, en especial cuando éste se acompaña de condiciones que hacen difícil su sostenibilidad. Todo el mundo conoce los tremendos retos que plantea un crecimiento acelerado de la población, sea cual sea su hábitat. Si bien, en los de índole urbana, los problemas, en apariencia, se presentan con más contundencia (Moriconi, 1993).

Un tema destacado y difícil de evaluar es la complejidad existente entre el lugar de residencia habitual y la movilidad urbana. Los residentes en torno a los núcleos urbanos principales realizan desplazamientos regulares o periódicos hacia ellos motivados por razones plurales: laborales, de ocio y consumo, familiares, u originados por otras causas. Ese sentido dinámico de la movilidad espacial (que origina las áreas funcionales urbanas) constituye una constante, si bien con diferentes intensidades, en las aglomeraciones urbanas. Los ciudadanos construyen el espacio urbano vivido y real a través de los impulsos individuales que llevan a cabo con regularidad (Dupuy, 1995). De ahí que para cualquier tarea de delimitación de los ámbitos urbanos es preciso contar con ello. Son entidades que señalan los lugares de residencia habitual, y aquellos otros vecinos o próximos, entre los cuales es posible calibrar flujos continuos de movilidad y desplazamiento (Bailly, 2002). En tal sentido, la prioridad alcanzada por el vehículo privado, automóvil, destaca con habitual desmesura frente a otros modos de viaje (Castañer et al. 2000).

Por ello, de manera palpable, y como aclaración acerca del procedimiento de trabajo utilizado para la delimitación del espacio correspondiente a las respectivas AAUU, debe añadirse que se sustenta en la doble combinación de aspectos: 
i) Se parte, en cada caso, de los municipios de mayor tamaño demográfico; completados con otros vecinos, que han registrado adiciones significativas de incrementos de población regulares en periodos recientes, superiores en un $50 \%$ a los promedios de otras áreas provinciales más alejadas. A los primeros se les consideran los nodos centrales de las correspondientes AAUU. Los segundos constituyen las áreas complementarias.

ii) A partir de ahí se trata de evaluar aquellos otros espacios que, en un cálculo razonable, quedan vinculados a ellos a través de las isocronas teóricas (Benoit et al., 2002). Éstas alcanzan una duración que puede oscilar entre los treinta minutos hasta casi una hora de viaje por cada desplazamiento, de acuerdo con la dimensión global de cada AU. La existencia de vías terrestres rápidas de gran capacidad, junto a otros ramales de tráfico complementarios, permiten en condiciones óptimas semejantes recorridos. Es cierto que tal amplitud temporal conlleva una cierta imprecisión. Pero, la realidad existente y su propia dinámica de evolución es tan abierta que, resulta imposible, si nos ajustamos a una interpretación correcta del espacio habitual vivido, intentar constreñirla con mayor minuciosidad ${ }^{3}$.

Las cartografías temáticas correspondientes del Ministerio de Fomento y de los servicios correspondientes transferidos a las CCAA, bien en sus publicaciones convencionales en papel, u otras formas, muchas de ellas disponibles en la red, han servido de gran ayuda a la hora de su delimitación ${ }^{4}$. También se utilizan algunas publicaciones, centradas en áreas singulares en cada caso. En suma, la combinación de esos elementos abre un camino de análisis complicado. A nadie se oculta que, en ciertos casos, puede llevar a cierta indeterminación. Pero es poco realista pretender formas de interpretación más exactas de la compleja realidad territorial. La aproximación general obtenida cabe evaluarla como satisfactoria.

Dado que la unidad de estadística en España se sustenta sobre la base municipal no tiene ningún sentido, en una investigación que abarca una escala territorial como ésta, escudriñar ni contemplar entidades inframunicipales. Sería más una cuestión de mero voluntarismo con escaso fundamento real. Así mismo, el número preciso de municipios a incluir en cada AAUU no constituye una evidencia axiomática. Afirmar lo contrario sería una aseveración exagerada. Aquí se presenta una propuesta de cuáles son las principales AAUU españolas (según su tamaño poblacional) para intentar abarcar una sustantividad, comprenderla y explicarla. Es probable que en alguna de las AAUU analizadas es posible añadir ún municipio más a los contabilizados, o restar otro. No creo que pueda señalarse con tajante exactitud los límites precisos de hasta dónde deben abarcar las AAUU. Con ello no se pretende relativizar lo que se hace; menos sublimarlo. Simplemente, se entiende que las ciencias sociales tienen unas claras limitaciones y, en este sentido, se muestran con toda su dimensión (Popper, 1962).

De manera concreta, como se especifica en el cuadro 1, el número de municipios englobados en cada AU resulta bastante dispar. La cantidad oscila entre 3 municipios en la correspondiente a Las Palmas de Gran Canaria y 74 en Barcelona. De las 17 consideradas, en 5 se contabiliza un total inferior a los 10 municipios, en los restantes los volúmenes son

3 Tomando como referencia general un espacio no sometido a discontinuidades destacadas ni interrumpido por accidentes naturales significativos, cabe afirmar que en la medida que los nodos de referencia básicos con mayores, la duración de las isocronas es más amplia; y viceversa. Eso explica la amplitud de las distancias existentes desde las periferias de las aglomeraciones a sus centros.

4 Tal es el caso del Atlas Estadístico de las áreas urbanas en España, Ministerio de Fomento, 2000. 
mayores. Ello obedece, tanto a la propia complejidad de la AU en cuestión, como a la dispar organización territorial de España ${ }^{5}$. Ahora bien, se considera que más significación que el número concreto de municipios, importa evaluar la extensión e importancia que representa cada AU, siempre en referencia con su conjunto provincial. Ello permite hacerse una idea mas ajustada del grado de polarización alcanzado y de la propia morfología y organización territorial interna de cada una. Se harán referencias oportunas a ello en varios casos.

Una última cuestión, que deseo traer a colación, se refiere al número de AAUU incluidas en esta investigación. En otros trabajos previos sobre el estudio de las AAUU en España en general (Serrano, 2006), se admite un total de cuarenta y cinco existentes en el conjunto nacional $^{6}$. Tal panorama permite evaluar la realidad territorial global, orientada hacia este mismo campo de la organización espacial. Sin embargo, dada la diferencia marcada en los tamaños dispares entre ellas, parece necesario establecer una neta diferenciación entre las que encabezan semejante jerarquía y el resto. De ahí que se evalúe que las de mayor tamaño muestren una realidad más compleja en su funcionamiento interno. Pero, sobre todo, son las más abultadas en población, quienes desempeñan un papel esencial, tanto por sus efectivos humanos acumulados, como por su equipamiento y dotación en general y el rol significativo que representan en el funcionamiento global de la organización territorial española. Ellas pueden considerarse como los espacios nodales españoles. La propuesta realizada, en los inicios de los noventa, dentro de la interpretación del sistema urbano español así lo señala (MOPTMA, 1993, Fig. I.3.1); casi coincide con esta, salvo las AAUU insulares y algún otro caso puntual. Los años transcurridos aportan algunos matices. Entre otros aspectos, destaca el dinamismo de su evolución; atendiendo a valores absolutos; su comportamiento sobrepasa ampliamente lo sucedido en el resto. Todo ello, las hace merecedoras de un análisis más pormenorizado, como aquí se intenta.

Puede ser discutible aquilatar el umbral neto de partida. Se elabora y presenta sólo una propuesta de trabajo. Las 17 englobadas indican una suma de población que se aproxima al medio millón de habitantes como umbral inicial. Por lo común, se estima que, en países de semejante envergadura a la española, cuando una entidad urbana se acerca a esa dimensión demográfica, es posible y resulta más fácil, desempeñar, con puridad, ese papel central apuntado. Aunque la relación presentada es concreta, siempre cabría la posibilidad de reducirla y modificarla en algún caso, eliminando alguna, o, aumentarla, añadiendo otra. De todas maneras, en el conjunto general sugerido, se advierte una cierta discontinuidad, entre las que encabezan la jerarquía y las que siguen en ella.

\subsection{Fases de evolución}

Para principiar con el análisis de los efectivos humanos residentes en ellas, nada mejor que mostrar dos cuadros de datos en los que se recogen sus valores absolutos, específicos, en los tramos temporales indicados, y sus variaciones (cuadros 1 y 2).

5 De sobra se conocen los acusados contrastes existentes en tal sentido en las provincias españolas. Mientras que en algunas sólo se contabilizan escasas decenas de municipios (Canarias, Cádiz, Murcia), en otras suman varios cientos, caso destacado son las provincias castellano leonesas. Detrás de todo ello se encuentran causas muy complejas, de índole histórica, en buena medida.

6 Para ello, empleando similar metodología, se tomaba un umbral demográfico en torno a los 100.000 habitantes residentes en ellas. 


\section{Cuadro 1}

\section{AAUU, EVOLUCIÓN DE LOS VALORES ABSOLUTOS}

\begin{tabular}{|r|l|r|r|c|r|r|c|c|c|c|}
\hline & & sup. km & \multicolumn{1}{|c|}{$\mathrm{N}^{\text {** }}$} & \multicolumn{1}{c|}{1950} & \multicolumn{1}{c}{1960} & \multicolumn{1}{c|}{1970} & 1981 & 1991 & \multicolumn{1}{c}{2001} & 2006 \\
\hline 1 & Madrid & $2.616,58$ & 41 & 1.731 .917 & 2.331 .153 & 3.599 .953 & 4.466 .597 & 4.676 .036 & 5.021 .708 & 5.494 .108 \\
\hline 2 & Barcelona & $1.336,37$ & 74 & 1.784 .292 & 2.337 .624 & 3.312 .089 & 3.894 .370 & 3.801 .248 & 3.797 .283 & 4.193 .830 \\
\hline 3 & Valencia & 1639,23 & 63 & 799.046 & 882.122 & 1.187 .145 & 1.436 .780 & 1.513 .237 & 1.557 .407 & 1.734 .884 \\
\hline 4 & Sevilla & 2422,02 & 29 & 529.065 & 641.278 & 792.377 & 991.337 & 1035560 & 1.146 .037 & 1.224 .555 \\
\hline 5 & Málaga C.Sol & $1.544,61$ & 15 & 392.348 & 425.149 & 537.889 & 753.353 & 857.961 & 1.001 .480 & 1.178 .951 \\
\hline 6 & Bilba0 & 1048,3 & 51 & 447.600 & 637.702 & 901.307 & 1039988 & 974.092 & 950.841 & 963.879 \\
\hline 7 & Ciudad Astur & $2.715,36$ & 24 & 563.113 & 673.821 & 782.033 & 874.399 & 881.476 & 878.776 & 900.450 \\
\hline 8 & Zaragoza & 2383,3 & 23 & 270.036 & 329.482 & 498.190 & 601.967 & 619.705 & 659.960 & 708.635 \\
\hline 9 & Alicante-Elche & 676,77 & 7 & 181.642 & 224.418 & 349.062 & 472.251 & 521.231 & 590.175 & 681.068 \\
\hline 10 & Cádiz.Jerez & 2000,89 & 6 & 302.432 & 368.242 & 428.825 & 520.589 & 561.426 & 577.756 & 617.488 \\
\hline 11 & Murcia & 1183,4 & 7 & 260.023 & 297.806 & 304.522 & 371.237 & 432.851 & 495.666 & 596.144 \\
\hline 12 & La Cor.-Ferrol & 781,91 & 18 & 319.926 & 381.636 & 413.188 & 483.344 & 503.495 & 523.088 & 549.241 \\
\hline 13 & Vigo-Ponteve. & 707,04 & 13 & 284.034 & 305.352 & 378.096 & 476.055 & 498.909 & 520.714 & 547.427 \\
\hline 14 & Palmas G. Ca. & 234,21 & 3 & 203.064 & 251.938 & 330.819 & 448.434 & 444.598 & 475.278 & 509.455 \\
\hline 15 & Granada & 781,54 & 29 & 246.725 & 250.923 & 293.699 & 366.612 & 402.130 & 442.373 & 476.928 \\
\hline 16 & Palma Mallor. & 662 & 9 & 153.013 & 177.618 & 241.310 & 323.645 & 344.092 & 412.607 & 472.123 \\
\hline 17 & San Sebastián & 490,45 & 20 & 103.671 & 267.736 & 376.802 & 432.160 & 422.026 & 434.266 & 448.884 \\
\hline & Suma total & $23.223,9$ & & 8.571 .947 & 10.784000 & 14.727306 & 17.953118 & 18.490073 & 19.485415 & 21.298040 \\
\hline & Total Pob. Es. & & & 28.172268 & 30.776935 & 34.041482 & 37.682355 & 38.872268 & 40.847371 & 44.395286 \\
\hline & \%TPE/AAUU & & & 30,42 & 35,03 & 43,26 & 47,64 & 47.56 & 47,70 & 47,77 \\
\hline
\end{tabular}

Elaboración propia sobre datos del I.N.E.; * número de municipios comprendidos.

Tal vez resulta una distorsión, necesaria, analizar el comportamiento de una realidad actual, las AAUU, con los valores de periodos anteriores, de hace décadas, cuando no puede hablarse de su existencia plena, semejante a la presente, ni tampoco de un funcionamiento tan integrado como tienen hoy. Precisamente, el transcurrir de los años, evidencia con sus variaciones de población, su propia consolidación. Ello confirma que, el paso a las entidades y realidades urbanas de ahora, no se produce de forma espontánea ni inmediata; por el contrario, se trata de un proceso largo. A veces con rápidos cambios, otras de forma más lenta. Sólo ese devenir permite aquilatar mejor la dimensión de lo acaecido y del panorama que vivimos.

Una idea clara, deducida al detenerse en la observación de los datos del cuadro 1, es que en el transcurso de la segunda mitad del siglo XX la significación de la población residente en estas AAUU se ha incrementado con fuerza. Pasa de 8,57 millones en 1950 a 21,29 en 


\section{Cuadro 2}

\section{AAUU, DIFERENCIAS TEMPORALES, VALORES ABSOLUTOS}

\begin{tabular}{|r|l|r|r|r|r|r|r|r|}
\hline & & \multicolumn{1}{|c|}{$1951-60$} & \multicolumn{1}{c|}{$1961-70$} & \multicolumn{1}{c|}{$1971-81$} & \multicolumn{1}{c|}{$1982-91$} & \multicolumn{1}{c|}{$1991-2001$} & \multicolumn{1}{c|}{$2002-2006$} & \multicolumn{1}{c|}{$1950-2006$} \\
\hline 1 & Madrid & 599.236 & 1.268 .800 & 866.644 & 209.439 & 345.672 & 472.400 & 3.762 .191 \\
\hline 2 & Barcelona & 553.332 & 974.465 & 582.281 & -93.122 & -3.965 & 396.547 & 2.409 .538 \\
\hline 3 & Valencia & 83.076 & 305.023 & 249.635 & 76.457 & 44.170 & 177.477 & 935.838 \\
\hline 4 & Sevilla & 112.213 & 151.099 & 198.960 & 44.223 & 110.477 & 78.518 & 695.490 \\
\hline 5 & Málaga- C. Sol & 32.801 & 112.740 & 215.464 & 104.608 & 143.519 & 177.471 & 786.603 \\
\hline 6 & Bilba0 & 190.102 & 263.605 & 138.681 & -65.896 & -23.251 & 13.038 & 516.279 \\
\hline 7 & Ciudad Astur & 110.708 & 108.212 & 92.366 & 7.077 & -2.700 & 21.674 & 337.337 \\
\hline 8 & Zaragoza & 59.446 & 168.708 & 103.777 & 17.738 & 40.255 & 48.675 & 438.599 \\
\hline 9 & Alicante-Elche & 42.776 & 124.644 & 123.189 & 48.980 & 68.944 & 90.883 & 499.426 \\
\hline 10 & Cádiz-Jerez & 65.810 & 60.583 & 91.764 & 40.837 & 16.330 & 39.732 & 315.056 \\
\hline 11 & Murcia & 37.783 & 6.716 & 66.715 & 61.614 & 62.815 & 100.478 & 336.121 \\
\hline 12 & La Cor-Ferrol & 61.710 & 31.552 & 70.156 & 20.151 & 19.593 & 26.153 & 229.315 \\
\hline 13 & Vig0-Ponteved. & 21.318 & 72.744 & 97.959 & 22.854 & 21.805 & 26.713 & 263.393 \\
\hline 14 & Palmas Gr Can & 48.874 & 78.881 & 117.615 & -3.836 & 30.680 & 34.177 & 306.391 \\
\hline 15 & Granada & 4.198 & 42.776 & 72.913 & 35.518 & 40.243 & 34.555 & 230.203 \\
\hline 16 & Pal. Mallorca & 24.605 & 63.692 & 82.335 & 20.447 & 68.515 & 59.516 & 319.110 \\
\hline 17 & San Sebastián & 164.065 & 109.066 & 55.358 & -10.134 & 12.240 & 14.618 & 345.213 \\
\hline & Diferencia.total & 2.212 .053 & 3.943 .306 & 3.225 .812 & 536.955 & 995.342 & 1.812 .625 & 12.726 .093 \\
\hline
\end{tabular}

Elaboración propia sobre datos del INE.

2006. Un incremento de 12,72 millones de personas (ver Fig. 1). En ese mismo tiempo el conjunto de la población española aumenta en 16,22 millones. La evaluación sencilla de ambas cantidades muestra que casi el ochenta por ciento $(78,42 \%)$ del aumento neto de la población nacional corresponde a los incrementos específicos concentrados en estas AAUU. De manera complementaria, otro cálculo que confirma esa misma idea se recoge también en el cuadro 1. En 1950 la población residente en ellas ascendía al 30,42\% del total; tras varias décadas de ascensos dispares, en 2006, esa proporción se evalúa en 47,77\%. Un aumento, pues, de 17,35 puntos.

De lo expuesto se deducen, entre otros, dos aspectos: de un lado, la segunda mitad del siglo XX ha sido un periodo acelerado de consolidación y crecimiento de las grandes AAUU en España. De otro, los últimos datos confirman el enorme peso y la elevada significación alcanzada ahora. Sólo en 17 AAUU, que suman una extensión de $23.223 \mathrm{~km}^{2}$, es decir, el $4,5 \%$ del territorio nacional, reside casi la mitad total de la población española.

Desde inicios del siglo comienza el auge del crecimiento urbano en España. Es un tema que ha sido de sobra estudiado desde las diferentes disciplinas sociales (Rodríguez, 1985). 


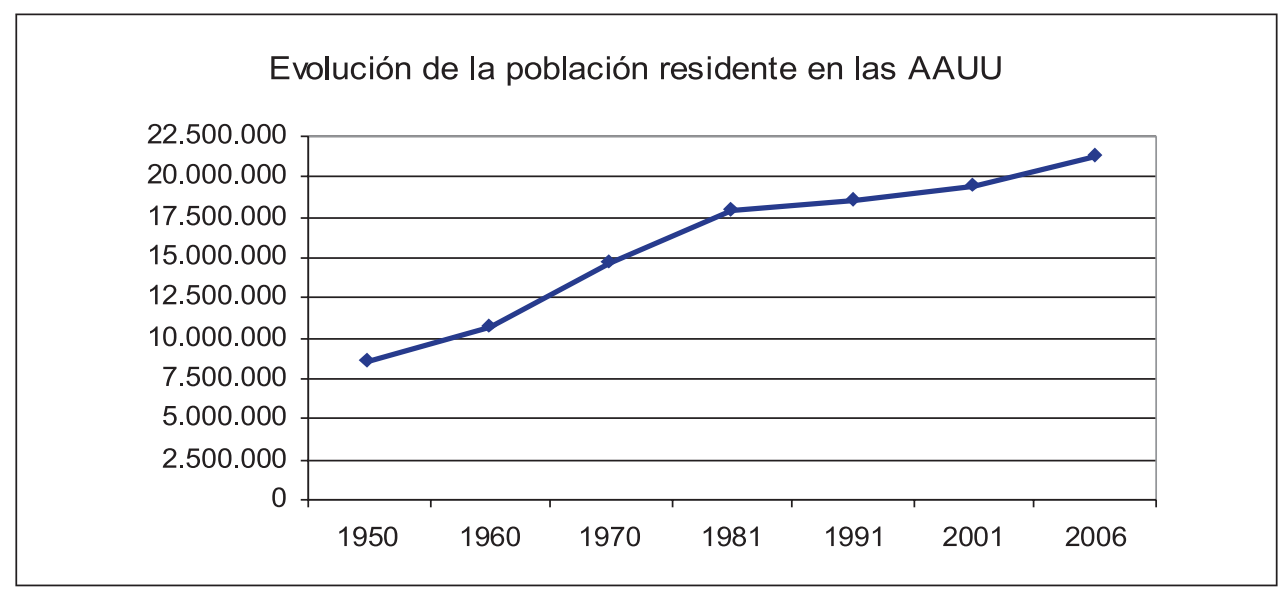

FIGURA 1

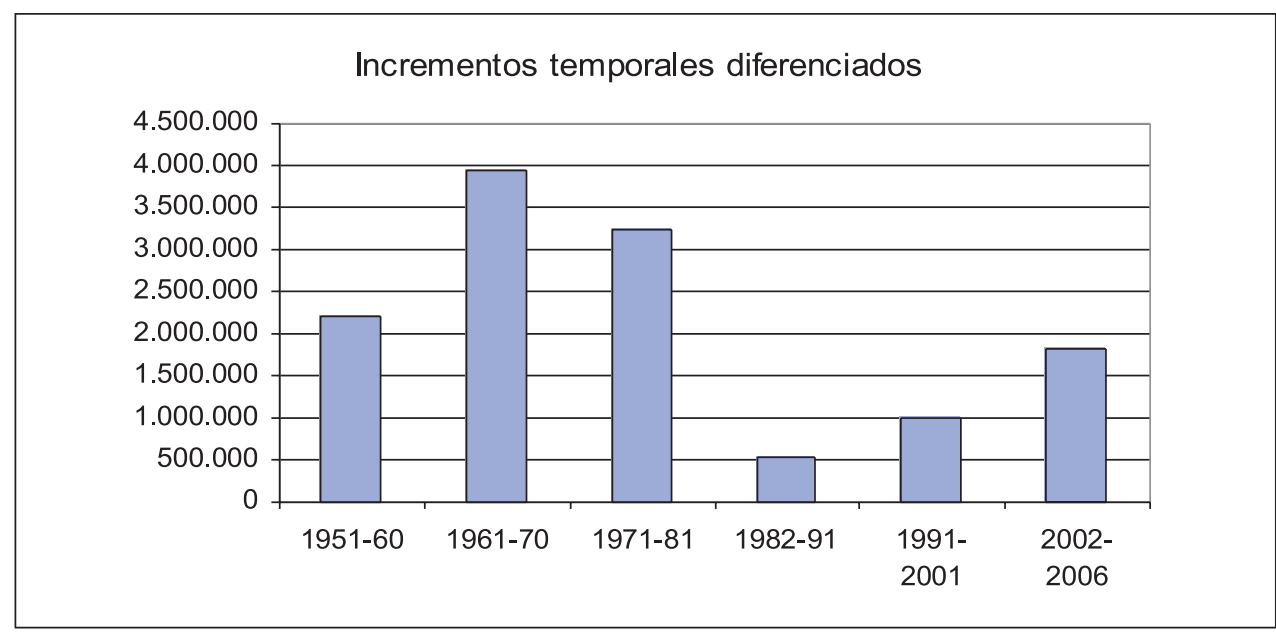

FIGURA 2

En su segunda mitad prosigue el ascenso imparable de la población residente en las citadas AAUU; su ritmo de aumento neto, así como su relación con lo que sucede, en referencia al conjunto nacional, aporta rasgos bien distintos (ver Fig. 2).

La primera década, los años cincuenta, contabiliza un aumento de 2,2 millones de personas. No cabe duda que es apreciable, pues representa un ascenso del $25,8 \%$ sobre la cantidad inicial, lo cual significa un horizonte de incremento superior al $2 \%$ anual. Otra consideración que enfatiza su importancia se desprende de cotejar ese aumento demográfico de las AAUU en referencia al conjunto de la población española. En esta década añade 2,6 millones de personas. Eso quiere decir que los residentes en las referidas AAUU elevan sus efectivos en una cantidad cercana a ella. Supone, en concreto el 84,6\%. Un valor considerable, si bien se sobrepasa en los dos periodos siguientes. Tras los duros años de postguerra, 
en que el conjunto de la sociedad y el sistema productivo español pugnan por encontrar una cierta normalización, en esta década se inicia una serie de cambios que trasladan sus efectos al territorio (Wright, 1978). Consecuencia claras de ello son la multilicación de los flujos migratorios interiores, el éxodo rural y el crecimiento urbano, con un claro protagonismo de las mayores ciudades y sus aledaños, como lugares de destino preferente (Rodríguez, 1987). A ello se añaden otros aspectos destacados, como el propio vigor general del crecimiento natural de la población, durante esos años (Nadal, 1984).

En el transcurso de los sesenta se registran destacados valores absolutos de crecimiento demográfico de las AAUU; los más cuantiosos de todas las décadas. En concreto el aumento suma 3,9 millones de personas. Esta cifra se magnifica aún más al cotejarla con la del ascenso global de la población española en ese tiempo, 3,26 millones. Ello significa que la población residente en los citados espacios urbanos (aquí considerados como tales), aumenta más que la del conjunto nacional; lo sobrepasa un veinte por ciento. De manera palpable eso corresponde a un comportamiento de clara polarización demográfica. Son los años cuando se registran los mayores flujos migratorios interiores en España (García, 1977); una buena parte de los cuales se dirigen hacia estos espacios urbanos; ahí radica una de las causas básicas que propicia semejante acumulación demográfica, como más adelante se tendrá ocasión de comentar con más detenimiento. Dentro de tal escenario general, lo sucedido debe valorarse como un aspecto más de las tremendas transformaciones que sufre el conjunto español a consecuencia del denominado proceso de desarrollismo, que alcanza entonces sus mayores índices de expansión (Fuentes Quintana, 1988).

El intenso incremento poblacional de las AAUU, acabado de referir, se amortigua algo, en la década siguiente, los setenta. Si bien dentro de ella es posible diferenciar los resultados de sus dos lustros, separados por la crisis económica y el inicio de los cambios políticos que aquejan a España. Ahora bien, el balance de esos diez años se cierra con una adición 3,6 millones de personas residiendo en ellas. Esa cifra significa el 88 por ciento del incremento demográfico español. Una proporción nada desdeñable y que, de nuevo, confirma la vitalidad demostrada por estos espacios urbanos para seguir acumulando efectivos humanos, dentro del balance general de la población española. Aunque el conjunto social, económico y político, que habían caracterizado los periodos anteriores, estaba llegando a su ocaso y mostrando ciertos reajustes, tal vez el impulso y su sesgo territorial, mantiene cierta inercia (Puyol, 1988). Las AAUU mantienen su papel como centros activos, prometedores y atractivos para muchas personas.

Tras esos 30 años de vivos incrementos de población, una cierta inflexión se produce en las dos décadas que siguen, los ochenta y los noventa. Veamos: en la primera, años 1982-91, los efectivos humanos residentes en las AAUU contabilizan sólo 0,5 millones de nuevos residentes. Un valor significativamente más reducido a los previos. Pero, incluso, conviene destacar que, dentro de un crecimiento demográfico nacional mucho más débil al de los periodos precedentes, la proporción alcanzada por las AAUU en él, se aminora de forma drástica. Se reduce al $43 \%$. Considerado de manera separada no se trata de un valor desdeñable, pero sí causa cierta extrañeza al cotejarlo con los antes indicados, donde se doblaba, e incluso triplicaba, semejante proporción. La combinación de una serie de causas plurales: descenso del crecimiento vegetativo global, evolución poco favorable de la economía y procesos intensos de reestructuración, con aminoración y cambios de signo en la dirección de los flujos migratorios (Miguel et al. 1985; Serrano, 1989), influyen, sin duda, en esa mudanza del balance general.

El paso de los noventa confirma un aumento de los nuevos valores que suman las AAUU. Se salda la década con un incremento de 0,99 millones de habitantes; casi el doble de lo conseguido en la precedente. El ascenso logrado, a su vez, representa algo más de 
la mitad (el 52\%) del aumento total de la población en esta década. De ello se deducen, pues, varios aspectos. De una parte, el conjunto de la población española muestra ciertos signos de recuperación, frente a la atonía que la presidía en la anterior. Ello se consigue gracias a que, si bien el movimiento natural continúa muy bajo, con tasas de natalidad que no consiguen remontar, a la vez que la mortalidad asciende, como consecuencia de una mayor tasa de envejecimiento, se inicia la llegada de inmigrantes exteriores, que, al paso de los años, constituye el elemento esencial de impulso de los efectivos humanos globales. A su vez, dentro de esa nueva arribada es preciso situar el aumento de la población de las $\mathrm{AAUU}^{7}$. Dado que una parte apreciable de los nuevos inmigrantes, que encuentran en el aglomerado de los servicios menos cualificados, sus principales ocupaciones, éstas se ofrecen en elevada proporción en las mayores AAUU; de ahí su renovado impulso (Pérez, et al., 2001). Por tanto, durante la década final del siglo, en valores porcentuales, las AAUU confirman tasas de crecimiento apreciables, aunque muy alejadas de las de los periodos anteriores. Al recuperarse el aumento poblacional general de España, las AAUU renuevan con brío su crecimiento.

Parecidas circunstancias, sólo que con renovados esfuerzos, concurren en el primer lustro del siglo XXI. En los años que van de 2002-2006 ${ }^{8}$, las mayores AAUU españolas añaden 1,8 millones de habitantes. Si hacemos una extrapolación a la década completa, sólo la de los años sesenta incorpora una cifra algo superior. Ello quiere decir que estamos viviendo años de intenso crecimiento de la población residente en las mayores AAUU españolas. La razón básica que impulsa esa dinámica es la antes apuntada: la llegada masiva de inmigrantes desde el exterior. Si bien es cierto que el aumento vegetativo se ha despegado ligeramente de la situación límite a que se había llegado en torno a los años de cambio de siglo, apenas contribuye por sí sólo al aumento demográfico que estamos tratando ${ }^{9}$. Por el contrario, durante los últimos años el ascenso creciente de los residentes extranjeros en España crece con intensidad. Ya se barajan cifras cercanas a los cuatro millones ${ }^{10}$. De todas maneras, se advierte ahora una peculiaridad destacada. La cifra de aumento de la población residentes en las AAUU, en referencia al crecimiento demográfico conjunto español, contabiliza una proporción cercana a la mitad (en concreto el 51\%). Representa un valor similar al registrado durante la década precedente. Su interpretación, se estima que reside en dos razones básicas, si bien de dispar naturaleza. Una, la copiosa llegada de residentes extranjeros — causa fundamental del crecimiento poblacional español— no hay que asociarla a que eligen de forma descompensada las mayores AAUU; pues se distribuyen por casi todas las ciudades. Pero, sobre todo, por ahora, confirman una distribución territorial regional

7 A mediados de la década de los noventa el número de residentes extranjeros en España comienza a crecer con fuerza. Basta unos datos elementales que sirven de confirmación de lo dicho: en 1990 ascendía a 407.647; en 1995 al aumentar a 499.772, sólo logra un ligero incremento. A partir de esta fecha sube con fuerza: 895.720 en 2000 y 1.109 .060 en 2001. Esos datos son los que contabilizan los valores correspondientes a residentes extranjeros registrados en los respectivos municipios españoles.

8 En concreto los del Censo de 2001 corresponden a 1 del 11; y los del Padrón continuo de 2006 a 1.1.

9 En estos momentos la tasa de crecimiento vegetativo apenas alcanza el 2 por mil, pues la natalidad en pocas regiones supera el 11 por mil, en tanto que la mortalidad se acerca al 9 por mil. Sólo algunas partes de España registran valores algo mayores, pero nunca tan destacados como para atribuirles una parte significativa en el citado aumento poblacional de las AAUU.

10 En primer lugar se utiliza el término de residentes extranjeros, toda vez que dentro de ese colectivo se engloban personas cuya llegada obedece a los motivos propios de las migraciones económicas, junto a otros que poco tienen que ver con esa condición, caso de los jubilados extranjeros, etc. En cuanto a su número absoluto, debe añadirse que no se preveía un auge tan espectacular. La actualización del Padrón de 2002 indicaba 1,9 millones; en 2003: 2,67; 2004: 3,03; 2005: 3,73, y en 2006: 3,88 millones. 
muy irregular ${ }^{11}$. De ahí su menor incidencia en el incremento singular de las AAUU. Otra, las fuertes tasas medias de crecimiento económico registradas por el conjunto de España engloban diferencias acusadas de unas regiones a otras, lo cual, como es lógico, representa una clara situación estructural diferenciada, que explica ese comportamiento general algo más moderado al aludido antes. Lo territorial prima sobre lo urbano.

\subsection{Un ejercicio de análisis y clasificación}

Un paso siguiente, de gran utilidad, consiste en intentar desentrañar dentro de las AAUU diferentes formas en su devenir temporal y sus resultados finales. Cualquiera es consciente de las dificultades que comporta en toda disciplina establecer reglas de uso general y observancia constante. Pero siempre ayuda a evaluar y comprender mejor toda realidad aproximarnos a ella desde esa óptica de análisis que busca agrupar, clasificar y ordenar los resultados, indagando, en su caso, la existencia de ciertas permanencias. Los elementos de referencia a seguir pueden ser varios; cada uno ayuda y proporciona su información. En su caso, su combinación armónica contribuye a alcanzar una visión más ajustada y completa de cuanto sucede.

Dadas las limitaciones de espacio, sólo se utilizan, a título de ejemplo, tres, muy dispares entre sí; todos contribuyen a alcanzar ese objetivo final apuntado.

\section{A) Núcleo central, tamaño y evolución}

Interesa hacer alguna aclaración. Se trata de estudiar en cada una de las AAUU, qué rasgos son comunes o diferentes a sus principales centros de población. En la mayoría de los casos coinciden con los respectivos municipios capitalinos de las correspondientes entidades provinciales. Éstos significan una proporción dispar, variable, que oscila entre el $30 \%$ y el $80 \%$ del total de la AU citada. Ambas cifras confirman un arco extenso, el cual nos indica la existencia de una amplia gama de situaciones. Eso muestra, una vez más, que la organización provincial, a través de sus centros capitalinos, ha sido determinante a la hora de la conformación posterior de las redes de AAUU, sean de tamaño más pequeño, o como en este caso, las de mayores dimensiones. Es un proceso que cuenta ya con casi dos siglos de historia, periodo durante el cual se han producido los mayores cambios y transformaciones socio-económicas y productivas, eso hace de las capitales provinciales los centros básicos de la organización territorial española (Serrano, 1986). En el caso que nos ocupa, cabría decir que estamos ante una serie de ciudades capitales de provincia, con mejores balances en su devenir singular, por la coincidencia de diversas circunstancias añadidas. A su vez, ello ha permitido trasladar su impulso de fomento, actividad económica y crecimiento demográfico, a sus entornos inmediatos. La suma de todo lo cual ha hecho posible, en definitiva, la existencia de AAUU de mayor tamaño.

Al proseguir con este análisis, se advierte que en ellas, además de la general primacía de tamaño demográfico y funcional aportado por el municipio central, el volumen destacado que alcanzan las AAUU se debe a la concurrencia de determinadas particularidades añadidas, empujadas directamente por ellas, hasta conseguir tal dimensión global. Es el caso de

11 Los contrastes regionales, en tal sentido, son acusados. Así, en valores de 2006, referidos al porcentaje de residentes extranjeros sobre el total de población, señalan claros contrastes. Los más reducidos corresponden a: Extremadura 2,30 \%; Asturias, 2,48; Galicia 2,50; País Vasco 3,42, etc. Frente a estos, los más copiosos son: Baleares 15,79 \%; Madrid, 12,94; Murcia, 12,32; Comunidad Valenciana 12,25; Cataluña 11,39, etc. Como puede evaluarse se trata de proporciones que superan la relación de uno a seis. 
Málaga, en referencia a su ámbito de expansión terciaria en la Costa del Sol próxima; el de Barcelona y sus perímetros industriales y terciarios; o el de Madrid, como generador de una extensa área urbana, de considerable repercusión en toda la península Ibérica (Serrano, King, 1995), etc.

Más que excepciones destacadas, acerca de lo indicado, es posible apuntar ciertas matizaciones que se apartan de ese devenir común. Por ejemplo: una de ellas, Vigo, centro básico de su aglomeración, no tiene ese categoría administrativa capitalina, aunque sí abarca, entre otros municipios, el de Pontevedra. En tres casos más, las AAUU correspondientes se han configurado a partir de la capital provincial respectiva, pero dentro de una cierta situación de mayor compensación aportada por otros municipios vecinos de considerable envergadura. Eso sucede en Alicante-Elche; Cádiz-Jerez y Oviedo-Gijón-Avilés. En estos casos, tales situaciones de partida, trasladan sus consecuencias a la propia morfología de la aglomeración, con situaciones singulares cercanas a la conurbación, en su caso, y con un funcionamiento marcadamente policéntrico de las mismas.

Por último, en este sentido, interesa recordar dos aspectos complementarios. Uno, que el número de municipios integrados en cada $\mathrm{AU}$ tiene que ver con situaciones históricas que influyeron en los modos de organización territorial (circunstancia ya referida), a lo que se añade también, lógicamente, que en la medida en que se trata de las AAUU de mayor tamaño, es normal abarcar un número mayor de municipios. Otro, que el grado e intensidad de las relaciones entre toda la $\mathrm{AU}$, en definitiva su nivel de integración interna, no es un asunto directamente dependiente del tamaño global de la misma, sino de la madurez que su evolución singular ha permitido; al amparo, en su caso, de una disposición morfológica propicia.

\section{B) Dimensión dispar y jerarquía}

Fijándonos sólo en los datos demográficos más recientes, los de la revisión padronal de 2006, las 17 AAUU seleccionadas no constituyen un todo homogéneo. Al contrario, es posible con facilidad percibir la clara jerarquía de tamaño que subyace en ellas. Incluso cabe diferenciar varios niveles urbanos. Analizar los datos de cada una, dentro de una perspectiva general, orientada a dilucidar las disparidades internas, dentro de su dispar dimensión, a la vez que su organización en niveles, todo ello constituye una tarea interesante y útil. Con suma brevedad se aportan algunas ideas al respecto.

En los niveles destacados de la jerarquía se incluyen las dos mayores, Madrid y Barcelona. Entre ambas y la siguiente existe una discontinuidad significativa. Pero, incluso, en las dos primeras, tampoco parece correcto señalar una paridad. Atendiendo al criterio poblacional, la AU madrileña sobrepasa a Barcelona con nitidez; por lo cual parece oportuno afirmar que ella (la AU de Madrid) ocupa el primer nivel. Dentro de la jerarquía urbana referida, el segundo le corresponde a Barcelona.

Estableciendo comparaciones, tanto con las precedentes, como las posteriores, destaca el tamaño de la AU de Valencia. Su tercer puesto parece así consolidado; de ahí la sugerencia de que le corresponde ese tercer nivel. Se trata de un diferencial de efectivos humanos entre ella y la que posterior, Sevilla en torno al medio millón de habitantes, además de otros aspectos de dispar naturaleza donde aflora una mayor complejidad en la primera que en la segunda (Salóm, 2001; Carrillo, 2003). Junto a valores absolutos deben contemplarse también los proporcionales.

Mayor homogeneidad entre sí muestran las cuatro siguientes, lo cual permite apuntar su inclusión en un nivel urbano más homogéneo, el cuarto. Son Sevilla, Málaga-Costa del Sol, Bilbao y Ciudad-Astur. Las diferencias de tamaño entre ellas señalan cifras que van 
de los cincuenta mil a los poco más de cien mil habitantes. Las diferencias son marcadas y peculiares en su morfología urbana, estructura de organización interna, así como, por supuesto, en lo referente a sus disímiles bases económicas iniciales que han fundamentado su ascenso demográfico. Su evolución histórica es más dispar que sus rasgos presentes. Pues ahora, las actividades terciarias, de una u otra naturaleza, como es común, constituyen sus bases económicas fundamentales.

Un quinto nivel lo engloban las diez AAUU restantes. Siguiendo con el mismo criterio demográfico existe una cierta gradación de una a otra, sin grandes saltos, donde apenas en los casos más destacados las diferencias superan la cifra de cincuenta mil habitantes. En varios casos entre una entidad urbana y la vecina jerárquica apenas se contabilizan unos pocos miles de habitantes. Otra cuestión distinta son los contrastes en sus tipologías singulares de organización urbana, significación y tamaño de sus cascos urbanos principales, complejidad de sus entornos periurbanos y la disposición y naturaleza de las correspondientes coronas urbanas de asentamientos. No obstante, al tratarse de una relación más copiosa, (son 10 AAUU), la diferencia de tamaño existente entre la primera, Zaragoza, y la última, San Sebastián, es considerable ${ }^{12}$.

\section{C) Evolución y dinamismo}

Es evidente que la consolidación y el destacado crecimiento demográfico de esta importante red de AAUU en España se ha afianzado en la segunda mitad del siglo XX. De manera escueta, en este ejercicio de estudio y análisis procede hacer algunas referencias a sus fases más destacadas: los años del despegue y posterior «desarrollismo» con su notable vigor, 1950-1970; los ochenta, mediante la atemperación de incrementos demográficos; los noventa, con el inicio de su nuevo auge y, finalmente, los años más recientes, ya en el siglo XXI. Se utilizan magnitudes porcentuales pues así resultan más comprensible su valoración.

Durante el tramo temporal conjunto (1950-2006), la población residente en las AAUU analizadas ha multiplicado sus efectivos en promedio de 2,4 veces. La base 100 de 1950 se ha convertido en 2006 en 248 (Vinuesa, 1996). Ahora bien, las diferencias de unas a otras es acusada; sobrepasan ampliamente ese ritmo: San Sebastián (432,9\%), AlicanteElche (374,9\%), Madrid (317,2\%) y Palma de Mallorca (308,5\%). En el lado contrario, los menores incrementos, muy por debajo del promedio general, corresponden a: CiudadAstur (159,9\%); Cádiz (204,1\%), La Coruña/Ferrol (171,6\%), Vigo-Pontevedra (192,7\%) y Granada (193,3\%). Las nueve restantes registran incrementos más cercanos al promedio general señalado.

Las tres décadas transcurridas entre 1950 y 1981, en que de nuevo, la población conjunta de las AAUU se duplica (la base 100 de 1950 se convierte en 209,4), de nuevo se contabilizan comportamientos muy dispares entre ellas. Así, se contraponen las elevadas proporciones de San Sebastián (416,8\%), Alicante-Elche (259,9\%), Madrid (257,9\%), Bilbao $(232,3 \%)$, Zaragoza $(222,9 \%)$ y Barcelona $(218,2 \%)$, a otras que sólo aumentan la mitad del promedio general de incremento poblacional: Murcia (148,5\%), Granada, (148,5\%), Ciudad-Astur (155,2\%). El resto registra valores equidistantes de ambos extremos. Parece sencillo advertir, de forma muy resumida, que los aumentos más intensos coinciden con

12 La relación de AAUU se cerró aquí, porque si bien es cierto que existen otros municipios urbanos españoles de notable tamaño, como Valladolid o Córdoba, no es menos cierto que carecen en sus entornos próximos de una trama urbana de suficiente entidad como para constituir una AU semejante a las aquí contempladas. 
aquellas áreas donde la industrialización y la terciarización alcanzó mayor vigor ese tiempo, y viceversa, débiles aumentos o incluso ajustes más fuertes por la crisis final.

Los años ochenta (es decir, entre 1982 y 1991) la población residente en las AAUU apenas crece un $3 \%$ (en concreto 2,99\%). Dentro de esa atonía general de los comportamientos demográficos, también se registran situaciones dispares entre ellas. Así, los más vigorosos, sobrepasan o se acercan al 10\%. Tales son: Murcia (16,6\%), Málaga-Costa del Sol $(13,8 \%)$, Alicante-Elche $(10,3 \%)$ y Granada (9,6\%). Lo novedoso en esta década es la aparición por primera vez de AAUU con retrocesos en sus efectivos humanos: Bilbao (-6,3\%), San Sebastián (-2,3\%), Barcelona (-2,3\%) y Las Palmas de Gran Canaria, que reduce sus efectivos en un simbólico $-0,85 \%$. De nuevo es necesario mencionar la crisis económica, años siguientes, y los numerosos cambios socio-políticos vividos por España durante ese tiempo, a los que antes se ha aludido, todos constituyen destacados inconvenientes que truncan la corriente al alza de su población. Donde aquellos son más fuertes su balance demográfico es peor (Serrano, Calmés, 1998, pp. 46 y ss.). Frente a eso, las AAUU con mayores aumentos demográficos se ubican en el cuadrante sureste español, pues la terciarización —en buena media el turismo - sirve de soporte a tales ascensos poblacionales (Alcaide, 1988).

La década de los noventa representa un crecimiento medio de los efectivos humanos residentes en las AAUU del 5,3\%. Ahora bien, ciertas AAUU saldan esos años con proporciones de aumento demográfico superiores, con valores que sobrepasan los dos dígitos; tal sucede en: Palma de Mallorca (19,9\%), Málaga-Costal del Sol, (16,7\%), Murcia (14,5\%), Sevilla $(10,6 \%)$ y Granada (10\%). De manera opuesta, hay tres AAUU que contabilizan retrocesos netos; si bien sólo uno es algo más palpable: Bilbao (-2,39\%), pues los dos restantes, son tan pequeños que casi es más apropiado hablar de situación de estancamiento: (Barcelona, $-0,10$ y Ciudad-Astur $-0,31 \%$ ). De todas maneras, la brecha existente entre ambos extremos de la relación jerárquica es notoria. Las tradicionales áreas industriales, ahora sometidas a dispares procesos de reconversión, registran perdidas de efectivos humanos, frente las del sur, más Baleares; todas estas reafirman su vigor demográfico, sustentado de nuevo en el atractivo que representa una terciarización activa, en la cual, de nuevo el turismo y actividades asimiladas afianzan su protagonismo (Zaldivar-Castells, 1992).

Los años transcurridos del presente siglo (2002-2006) apuntan un renacer considerable del incremento poblacional de estas AAUU. Es necesario retroceder varias décadas para encontrar balances tan positivos. Ahora bien, es posible igualmente diferenciar ritmos de evolución contrastados. Sobre el promedio global del 9,3\%, se perciben situaciones de mayor dinamismo, superando o acercándose al doble de ese umbral tan elevado; los más intensos corresponden a: Murcia (20,2\%), Málaga-Costal del Sol (17,7\%), Alicante-Elche $(15,4 \%)$, Palma de Mallorca $(14,4 \%)$ y Valencia $(11,4 \%)$. Los aumentos más endebles, bastante inferiores al incremento medio, pertenecen a: Bilbao $(1,3 \%)$, San Sebastián (3,3\%), Ciudad-Astur (2,4\%), La Coruña-Ferrol, $(5,0 \%)$ y Vigo $(5,1 \%)$. Situando en un mapa la ubicación de unas y otras AAUU, ayuda a reflexionar acerca cuáles son las motivaciones económicas esenciales y sus actividades productivas básicas, para colegir los modelos de crecimiento que aparecen primados, durante estos años, y cuál se comporta con cierto letargo; todo ello dentro de un ciclo global de ascenso demográfico, sostenido por unas tasas de crecimiento económico apreciables. No obstante, se advierte que éstas afectan de manera dispar a cada una. Las actividades ligadas a los servicios, el turismo, ocio, tiempo libre y la construcción (en parte asociada a esos aspectos) aportan mayores beneficios de ascenso, y corresponden a las AAUU situadas en el arco mediterráneo, en su cuadrante sureste, extendido a las Baleares. En tanto que, las opuestas, de nuevo confirman la mayor debilidad que registran las AAUU situadas en toda la cornisa cantábrica, 
desde Galicia a las Vascongadas, para participar de ese elevado dinamismo demográfico (Nel.lo, 2004).

Por consiguiente, este breve análisis de varios aspectos relacionados con el aumento diferenciado de la población de las AAUU, en sucesivos periodos temporales, abunda en asuntos ya señalados, algunos comunes, si bien, en años recientes, adquieren otro sesgo e intensidad. Todo ello permite comprobar y comprender cómo las dispares formas de crecimiento de los efectivos humanos, encuentran una clara correlación con otra serie plural de variables, sociales y económicas. No en balde, el comportamiento de la población urbana siempre marcha ligado a fuerzas complejas que terminan y comienzan en decisiones particulares (Bourdin, 2005).

Lo que acaba de exponerse, sirve de pequeña muestra que ayuda a recordar que tras un proceso global que indica un fuerte incremento de la población residente en las AAUU, sus ritmos temporales, difieren entre sí de forma notable. A menudo, incluso, se contraponen. Si se prosigue en el análisis más detallados, incluso pormenorizados, de cuanto sucede, es factible encontrar una lógica que explica las principales causas y razones que hay detrás de todo ello. Nada hay fortuito; menos aún en todo lo referente a la dinámica que justifica y ayuda/dificulta la evolución de la población de las entidades urbanas de considerable tamaño, como las aquí estudiadas.

El rápido ritmo de crecimiento y las nuevas formas que lo caracterizan, nos introducen en un nuevo escenario cuya dimensión no es en exclusiva de cantidad; lo es más de cualidad. El panorama presente de las AAUU se distingue por modificaciones sustanciales en su estructura y organización. Este nuevo panorama abre una realidad muy compleja, sobre la cual sólo es posible añadir algunas consideraciones, como se hace a renglón seguido.

\section{Perspectivas próximas y consideraciones finales}

Toda prospección sobre el devenir es aventurada. El caso que nos ocupa no es una excepción. Antes al contrario, son tantos los elementos que participan y de diferente naturaleza, que convierte en mero voluntarismo evaluar el acontecer de estas cuestiones.

Todo ello es necesario contemplarlo dentro de una escala de análisis supranacional (Sassen, 1994). La interrelación de España en ese contexto es creciente. Pero, las limitaciones de su dimensión interna y sus condiciones estructurales, acentúan su dependencia del exterior y su debilidad. A pesar de que mantiene unos parámetros de bienestar de los más elevados del planeta (Ontiveros, 2007). Frente a esas cuestiones poco favorables, hay otra de signo opuesto. El anclaje que España mantiene dentro del conjunto de la Unión Europea es palpable. Desde su ingreso en la Unión en 1986, no ha hecho más que participar, cada vez con mayor fuerza, en ese devenir conjunto, integrándose de manera progresiva en sus diferentes apartados. Este aspecto aporta una cierta seguridad, dada la envergadura y significación de aquella en el contexto mundial. De ahí la conveniencia de reflexionar sólo acerca de la realidad hoy existente, en un doble sentido:

a) Evaluar lo que significa (en cuanto al conjunto de las principales AAUU) como un activo para el conjunto español, dentro de una consideración positiva.

b) Calibrar algunos de los principales problemas que se plantean, dada su evolución actual; si bien éstos se pueden ver alterados, en uno u otro sentido, en función de las modificaciones futuras que puedan producirse. A ello se dedican las próximas líneas. 


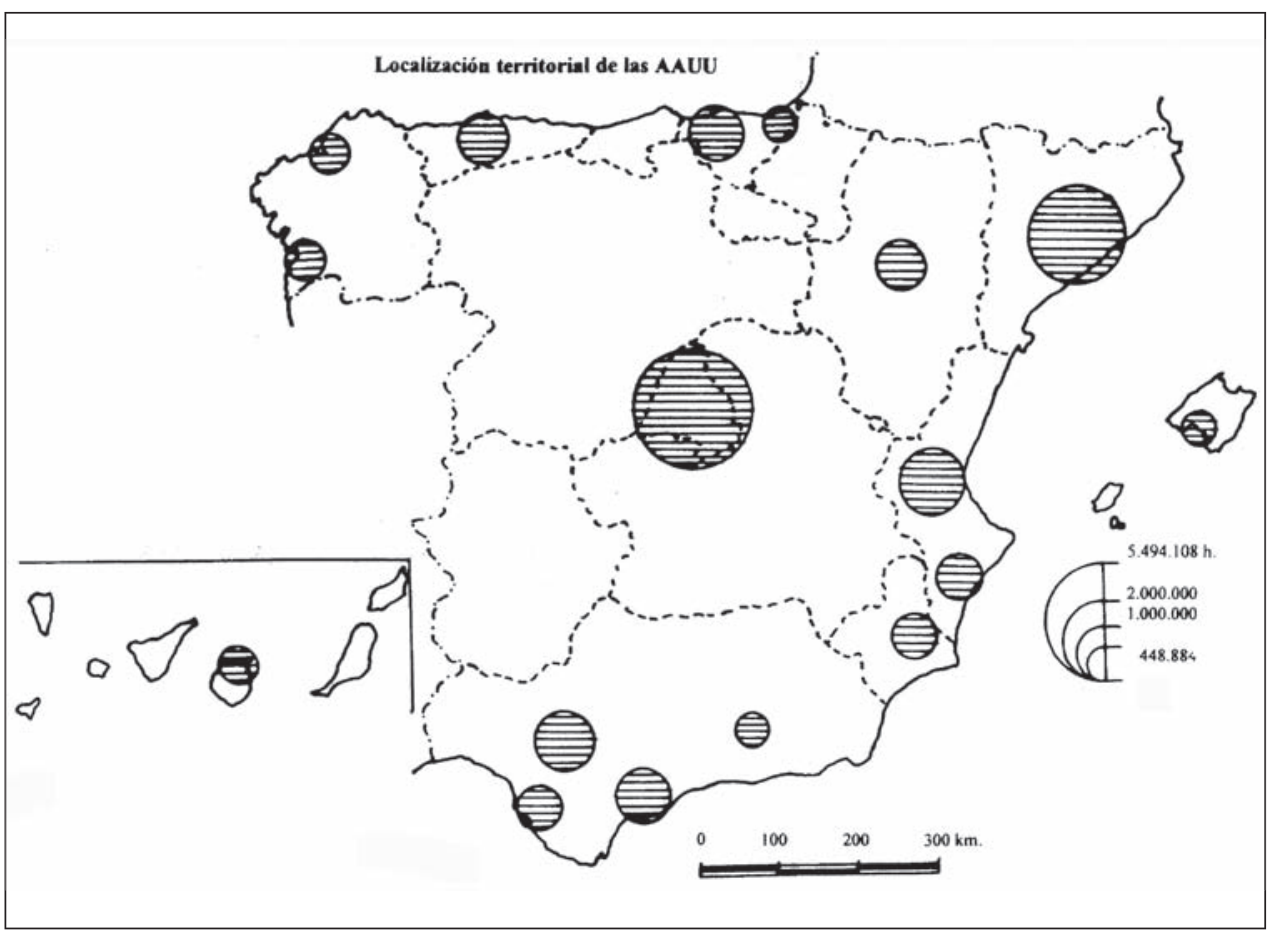

FIGURA 3

Dentro de lo que se puede indicar, en tanto que elementos favorables y positivos, se encuentran diferentes aspectos relacionados con su consideración territorial. La disposición espacial de las AAUU, estudiadas, no conforman una red regular de nodos, ni una trama urbana armónica, pero abarcan casi todo el conjunto español (Fig. 3). Incluso los dos archipiélagos no quedan fuera; pues cada uno cuenta con su centro respectivo. Pero el vacío central en torno a la AU madrileña es demasiado notorio. Quizás, la progresiva consolidación de esta red de nodos urbanos básicos ha evitado situaciones de mayor polarización territorial, de los cuales tenemos ejemplos, de diferente magnitud, en algunos de los países de nuestro entorno inmediato.

Estimo que estas AAUU constituyen centros de gran vitalidad y dinamismo, cada uno funciona con cierta autonomía. Interesa recapacitar en que, cuando una entidad urbana alcanza un determinado tamaño y una cierta complejidad en su organización, resulta más sencillo crear mecanismos propios, aminorando su dependencia de otros centros urbanos mayores, las unidades rectoras del sistema urbano donde está incardinada (Elizagarate, 2003). En buena medida esto afecta a la casi totalidad de las AAUU analizadas.

Otro aspecto positivo, inherente a la dimensión y naturaleza de estas AAUU, es que todas ellas, aunque con diferente nivel e intensidad, aportan la posibilidad de actuar como centros difusores en el dinámico proceso de cambio que caracteriza nuestra sociedad actual (Storper, 2007). Las ciudades son siempre los centros de la innovación; camino para el cual no hay límites. El capital humano, principal recurso con el que cuentan, constituye en nuestro tiempo, el activo más precioso. Garantiza una cierta tendencia hacia la propia diversificación, evitando así situaciones de difícil salida, de crisis o estancamiento, en definitiva. 
Su dimensión singular, junto a las áreas de influencia que cada una consigue aglutinar, representa un mercado con una demanda notable, acrecentada en la media en que se eleva el nivel medio de vida de su población. Todo ello hace posible que los correspondientes equipamientos funcionales se amplíen y completen. No es extraño, pues, encontrar en todas estas AAUU dotaciones funcionales de bienes de rango elevado. De tal suerte, su oferta es tan amplia que, de facto, cada una de ellas termina comportándose como un centro regional de abastecimientos plurales para las respectivas poblaciones residentes en sus correspondientes espacios de influencia. Todo ello, dentro de una interpretación actual que imponen los nuevos tiempos y sus tremendos cambios tecnológicos (Castells, Hall, 1994). Ahora bien, no hay que olvidar que semejante dinámica territorial puede encontrar un cierto freno. Tal es el caso de la actual organización territorial autonómica. Todas aquellas funciones de naturaleza pública que precisan para su consumo y disfrute una acción presencial y participe de manera obligatoria cualquier aspecto relacionado con la organización política y administrativa, las correspondientes capitales autonómicas tienden a ejercer un protagonismo primado sobre sus territorios (Serrano, 1994). Interesa recordar que, salvo algunas excepciones, todo el sistema autonómico español funciona territorialmente con una concepción centralista palpable ${ }^{13}$. Esto, sin duda, ha favorecido el auge de varias de las AAUU aquí analizadas (9 de 17); pero quizás ha menoscabado el de aquellas que no lo son (las 8 restantes). Esta pugna y su correspondiente dinámica de fuerzas no están cerradas; al revés, se muestran más abiertas que nunca. Sus resultados pueden variar y encaminarse en dispar dirección.

De otro lado, las AAUU estudiadas se enfrentan a una serie destacada de problemas y dificultades. Muchos de ellos constituyen retos difíciles de solucionar. Todo hace pensar que éstos continuarán durante los próximos años. Pueden agravarse si las condiciones son desfavorables y si continúan ritmos acelerados de crecimiento y expansión como ha ocurrido durante los años precedentes. No procede aquí hacer un análisis detenido de todos ellos, no es la ocasión, ni se dispone del espacio suficiente para abordarlo. Sólo se intenta aportar algunas consideraciones finales en consonancia con lo que parecen ser sus perspectivas más inmediatas de comportamiento.

Una idea de fondo, sobre la que se debe reflexionar, concierne al modelo de ciudad predominante hacia dónde se camina. Se advierte que el tradicional concepto de ciudad europea, según su concepción amplia, encuentra serias dificultades en su pervivencia. Todas las ciudades del planeta tienden a ser más parecidas (Paciones, 2001). En su estructura interna cada vez se avanza más hacia modelos policéntricos con horizontes mega-urbanos. Las AAUU analizadas, si bien en diferente grado y manera, constituyen una constatación de ese devenir.

Ahora bien, tales aspectos no deben eliminar políticas y actuaciones que propendan a conservar y potenciar muchos rasgos que forman parte de la memoria y del imaginario colectivo de nuestras viejas ciudades. Resulta difícil encontrar un acertado equilibrio entre las numerosas transformaciones planteadas. A nada conduce idealizar formas urbanas pretéritas, ni impedir otras nuevas que se barruntan. Por ello, se impone, más que nunca, centrarse en los modelos urbanos que están desarrollándose y en los problemas básicos inherentes.

No debe olvidarse que cada vez más las grandes entidades urbanas, pobladas por cantidades elevadas de personas, además de espacios de convivencia, son lugares de trabajo y producción económica, conectados a un sistema de funcionamiento mundial (Veltz, 2003).

13 Se tiene la sensación de que salvo excepciones, cada Comunidad Autónoma, reproduce como modelo centralizado la organización tradicional, mediante la cual concentra en su capital el mayor número de funciones posibles, favoreciendo modelos de polarización territorial. 
Su dimensión y protagonismo internacional se acrecienta. Pero, ello no debe postergar su integración convivencial interna y su auténtico sentido genérico de ciudadanía, aspecto esencial siempre (Borja, Castells, 1997, p. 363). La copiosa y brusca llegada de decenas de miles de extranjeros a las AAUU españolas augura numerosos desajustes y problemas, pendientes por ahora. Conviene afrontar tales cuestiones con el máximo rigor, fuera de fáciles demagogias que a poco conducen.

En las AAUU actuales son comunes nuevas formas de hábitat urbano, entendido en su concepción más amplia. En todas ellas, en especial en las de mayor tamaño, se viven procesos contrapuestos y complementarios. Junto a la gentrificación se advierten claros síntomas de crecimiento periurbano y rururbano, con la consolidación de plurales coronas urbanas, en torno a las cuales son frecuentes tipologías y modelos propios de la ciudad difusa, con claras fragmentaciones de los espacios urbanizados. Dentro de eso no son menos importantes los casos de aparición de ciudades cerradas, junto a ejemplos semejantes a las «edge cities» que aporta Garreau, (1991), ya referido a España (Sorribes, 1999). Al mismo tiempo, en su dimensión intraurbana aparecen también nuevas y radicales transformaciones de todo tipo, muy diferentes, en sus contenidos y sus problemas a la realidad precedente.

La adición de unos elementos y otros genera siempre espacios urbanizados crecientes y mayores consumos de suelo, que, a su vez, trasladan sus consecuencias a otros ámbitos complementarios, necesarios para su cotidianidad, como los de índole energética, necesidades de agua, etc. Lo cual nos introduce en el candente asunto de los límites urbanos futuros y su difícil sostenibilidad; en especial, si se prolonga su continua y rápida expansión espacial, como ha ocurrido en años recientes (Merlin, 1996).

La disponibilidad de un parque inmobiliario de calidad, que sirva de manera adecuada como residencia a esas numerosas poblaciones, en constante aumento durante sus últimos años, constituye una cuestión central, que aporta mayor seguridad y armonía en el futuro de las AAUU españolas (Arias, 2007). A los colectivos más débiles, por su menor poder adquisitivo, su horizonte de vida limitado o a causa de la adición de otras condiciones adversas, les resulta difícil seguir las pautas que marca el mercado. De ahí que sea conveniente llevar a cabo políticas de vivienda que contemplen, en su caso, situaciones subsidiadas para aquellos colectivos más desfavorecidos. De lo contrario, si las ciudades prosiguen su fuerte ritmo de crecimiento con el horizonte actual, estos asuntos pueden desbordarse, creando serias tensiones y problemas en el vivir cotidiano.

Otro problema notorio de las AAUU es el apartado genérico de las infraestructuras. En un sentido amplio abarcan todo tipo de transportes, comunicaciones y demás servicios prestados a la comunidad para la calidad de su vida cotidiana, tales como suministro de agua, combustibles, tratamiento de residuos y demás equipamientos, etc. A nadie se oculta que en una sociedad desarrollada, que pretende mantener elevados niveles de calidad de vida, ello precisa inversiones constantes para mantener y mejorar estos servicios. De nuevo, es apurado encontrar un equilibrio entre los intereses privados y públicos. Todas esas cuestiones alcanzan especial gravedad cuando se trata de entidades urbanas en continuo y vivo crecimiento. Al incorporarse anualmente decenas de hectáreas urbanizadas las necesidades de inversión se multiplican. También se añaden dificultosos problemas a la hora de renovar y ensamblar los centros urbanos tradicionales con estas nuevas áreas de expansión. Además, interesa tener presente que no sólo se trata de buscar una eficacia en su funcionamiento, ya de por sí algo importante, también se precisa ofrecer una dimensión de imagen. En un mundo urbano tan competitivo como el nuestro, donde el marketing urbano presenta en la excelencia de calidad de su oferta uno de los principales reclamos, cualquier conflicto serio en estas cuestiones puede ser nefasto. Todos estos asuntos deben contemplarse siempre dentro de un doble parámetro de incidencia: interna y externa (Berg et al., 1995). No 
basta plantear estos apartados de manera tradicional, al limitar este campo, sobre todo a los transportes y la accesibilidad, con vistas a las inversiones productivas (Serrano, Schliephake, 2004); y, en caso negativo, a sus correspondientes consecuencias de deseconomía. Todo ello sigue teniendo validez, pero exige, acaso con más fuerza, acompañarlo de otras consideraciones complementarias.

Lo relativo a la fiscalidad alcanza en las AAUU una enorme significación. En el caso español se añaden otros aspectos singulares. Los problemas, en esencia, adquieren una doble naturaleza: una referente a su dimensión, niveles y, en suma, acerca de la disponibilidad de efectivos suficientes. Otra, sobre titularidad, armonía y homogeneidad. Se demanda con harta frecuencia la participación de los poderes públicos para atender numerosas cuestiones que afectan a los aspectos más variados de la vida cotidiana urbana. Todo ello sólo puede atenderse desde una fiscalidad que sea capaz de recaudar suficientes recursos. Pero, en España, se ha desarrollado una notoria descompensación entre sus niveles político-administrativos, estatal, autonómico y local, en detrimento del último ${ }^{14}$. A menudo se exige lo imposible: prestar demasiados servicios para la capacidad recaudatoria existente. Estos asuntos se ven especialmente enfatizados en lo que concierne a los grandes municipios urbanos, y de manera palpable, en las AAUU y demás entidades de similar naturaleza y envergadura. Los déficits habituales registrados sólo se intentan solucionar de manera transitoria. Otra cuestión antes anunciada alcanza su mayor conflictividad en la base municipal de la organización local. Dada la pluralidad de municipios englobados en cada AU lo más común es la carencia de armonía fiscal entre ellos; incluso, a menudo, se producen casos evidentes de desajustes. No son ajenos a todo ello los legítimos y dispares planteamientos políticos que llevan a estos asuntos sus confrontaciones habituales. A nadie escapa que pueden derivarse ciertas pugnas en la vida regular de las AAUU, con tratamientos heterogéneos que, a la postre, perjudican el devenir de los conjuntos urbanos.

De lo antes expuesto, es fácil deducir situaciones complejas y complicadas derivadas de la gobernanza de las entidades urbanas (Lefèvre, 2003). Estas entidades urbanas supramunicipales no existen en España, desde una perspectiva legal, ni están amparadas por el derecho positivo. La única figura a la que se suele hacer referencia para acogerse es la conocida de las «mancomunidades de municipios», después del desmantelamiento y la supresión de otras figuras formales de naturaleza metropolitana. Ello no resulta suficiente. De ahí la necesidad de conocer y tomar conciencia de la realidad que representan estas entidades, las AAUU, con los problemas inherentes que plantean y las soluciones que precisan. A partir de ahí es necesario articular ciertas fórmulas de coordinación que, como objetivo final, no dejen de lado articular determinadas acciones de gobernanza común. Muchos de ellos no se pueden solventar desde los correspondientes ámbitos municipales. De lo contrario las disarmonías que aparecen y los problemas existentes serán mayores. No se postula crear nuevas estructuras burocráticas de gobierno, que tal vez no serían del todo operativas. Acaso es mejor tender hacia comportamientos más prácticos que contemplen situaciones concretas, creando su propia dinámica de funcionamiento al resolverlos. Si se emprende un camino de solucionar problemas conjuntos, cabe pensar que la mayoría estará interesada en solventar asuntos que afectan a todos.

14 Si se compara la distribución de la capacidad de gasto de los principales niveles administrativo entre España y otros países equiparables en su modelo territorial, se advierte que sólo el nivel local es el que encuentra menor capacidad, frente al autonómico-regional y el estatal. 


\section{Bibliografía}

ALCAIDE, J. (1988): «Las cuatro Españas económicas y la solidaridad regional». Papeles de Economía Española, $\mathrm{n}^{\circ} 34$, pp. 246-262.

ARIAS, A. (Coord.), (2007): Atlas estadístico de la construcción en España. Ministerio de Fomento, Madrid, $95 \mathrm{pp}$.

BAILLY, M. J. (2002): Le temps des villes. Pour une concordance des temps dans la cité. Conseil Économique et Sociale, Republique Français, París, 140 pp.

BENOIT, J.M.; BENOIT, Ph. \& PUCCIE, D. (2002): La France á 20 minutes (et plus). La révolution de la proximité. Belin, París, 271 pp.

BERG, van den, L. \& KLINK, A. van (1995): «Planificación estratégica y márketing urbano». Situación, no 3, Banco de Bilbao-Vizcaya, pp. 39-53.

BORJA, J.; CASTELLS, M. (1997): Local y global. La gestión de las ciudades en la era de la información. Taurus, Madrid, $417 \mathrm{pp}$.

BOURDIN, A. (2005): La métropole des individus. Éditions de l'Aube, París, 250 pp.

BUNGE, M. (1983): La investigación científica. $2^{\mathrm{a}}$ ed. Ariel, Barcelona, $955 \mathrm{pp.}$

CARRILlO, E. (coor.) (2003): Atlas, Sevilla Metropolitana. Sevilla Global, Agencia Urbana de Promoción Económica, Sevilla, 130 pp.

CASTAÑER, M.; VICENTE, J. \& BOIX, G. (eds.) (2000): Áreas urbanas y movilidad laboral en España. Universitat de Girona, Girona, 164 pp.

CASTELLS, M. \& HALL, P. (1994): Las tecnópolis del mundo. La formación de los complejos industriales del siglo XXI. Ed. esp., Alianza Editorial, Madrid, 360 pp.

CASTELLS, M. (1995): La ciudad informacional. Tecnología de la información, reestructuración económica y el proceso urbano regional. Alianza Editorial, Madrid, $492 \mathrm{pp}$.

DUPUY, G. (1995): Les territoires de l'automobile. Anthropos, París, 216 pp.

ELIZAGARATE, V. (2003): Marketing de ciudades, Ed. Pirámide, Madrid, 193 pp.

FUENTES QUINTANA, E. (1988): «Tres decenios de economía española en perspectiva». En España, Economía, (dir.) J.L. García Delgado, Espasa-Calpe, Madrid, pp. 1-78.

GARCÍA BARBANCHO, A. (1977): Las migraciones interiores españolas, 1961-1970. Instituto de Estudios Económicos, Madrid 120 pp. más apéndice estadístco.

GARREAU, J. (1991): Edge city. Life in a new frontier. Doubleday, Nueva York, 546 pp.

HALL, P. (2006): «Introducción», en: Actas, Congreso Regionales Capitales, Comunidad Autónoma de Madrid, Madrid, pp. 15-17.

LABORDE, P. (2005): Les villes espagnoles. Presses Universitaires de Bordeaux, Burdeos, 214 pp.

LEFÈVRE, Ch. (2003): «La planificación de las metrópolis europeas. Entre gobierno y gobernanza». Urban, $\mathrm{n}^{\circ}$ 8, Madrid, pp. 78-92.

MARSHALL, J.U. (1989): The structure of Urban Systems. University of Toronto Press, 394 pp.

MASSEY, D.; ALLEN, J. \& PILE, S., (1999): City Worlds, Routledge, Nueva York, 348 pp.

MERLIN, P.; TRAISNEL, J.P. (1996): Énergie, environnement et urbanisme durable. P.U.F., París, $322 \mathrm{pp}$.

MIGUEL, M. de; DIÉZ NICOLÁS, J. (1985): Políticas de población. Espasa-Universitaria, Madrid, 302 pp.

MINISTERIO DE OBRAS PÚBLICAS, TRANSPORTES Y MEDIO AMBIENTE (1993): Plan Director de Infraestructuras, 1993-2007. Secretaría General Técnica, Madrid, 426 pp. más figuras.

MORICONI-EBRARD, F. (1993): L'Urbanisation du Monde, despuis, 1950. Anthropos, París. 371 pp.

NADAL, J. (1984): La población española. (Siglos XVI a XX). Ariel, Barcelona, 266 pp.

NEL.LO, O. (2004): «¿Cambio de siglo, cambio de ciclo? Las grandes ciudades españoles en el umbral del siglo XXI». Ciudad y Territorio. Estudios Territoriales, Madrid, nºs 141-2, vol. XXXVI, pp. 523-542.

ONTIVEROS, E. (2007): «Sostenibilidad y convergencia real». Economistas, n 111, Madrid, pp, 29-32.

PACCIONE, M. (2001): «The future of the city. Cities of the future». Geography, pp. 275-286. 
PÉREZ-DÍAZ, V., ÁLVAREZ-MIRANDA, B., GONZÁLEZ-ENRÍQUEZ, C. (2001): España ante la inmigración. Fundación La Caixa, Barcelona, 240 pp.

PONCE HERRERO, G. (ed.) (2006): La ciudad fragmentada. Nuevas formas de hábitat. Publicaciones de la Universidad de Alicante, Alicante, $253 \mathrm{pp}$.

POPPER, K.R. (1962): La lógica de la investigación científica. Ed. esp., Tecnos, Madrid, ed. consultada, 6a 1982,294 pp.

PRECEDO, A.J. (2004): Nuevas realidades territoriales para el siglo XXI. Desarrollo local, Identidad territorial y ciudad difusa. Síntesis, Madrid, 207 pp.

PUYOL, R. (1988): La población. Síntesis, Madrid, 157 pp.

RODRÍGUEZ, J. (1985): Población y territorio en España. Siglos XIX y XX. Espasa Universitaria, Madrid, $219 \mathrm{pp}$.

RODRÍGUEZ, J. (1987): Proceso de urbanización y desarrollo económico en España». En: Los problemas urbanos en España, Ed. Orbis, Barcelona, pp. 53-90.

SALOM, J.; DELIOS, E. (2001): «Movilidad laboral como criterio de delimitación territorial: su aplicación a la Comunidad Valenciana». En: Áreas urbanas y movilidad laboral en España. M. Castañer, Vicente, J., Boix, G. (eds.). Universitat de Girona, Girona, 37-59.

SASSEN, S. (1994): Cities in a World Economy. Pine Forge Press, Thousands Oaks, Can. Mas., $157 \mathrm{pp}$.

SEGURA SANZ, R. (coord.) (2000): Atlas estadístico de las áreas urbanas en España. Ministerio de Fomento, Madrid, 182 pp.

SERRANO, J.M ${ }^{\text {a }}$ (1986): «Las ciudades capitales de provincia en España. Un crecimiento primado e ininterrumpido». Estudios Territoriales, M.O.P.U., Madrid, nº 22, pp. 125-146.

- (1989): «L'Espagne: Les disparitès régionales dans la densité de population en 1986. ¿Fin d'un processus d'augmentation des désequilibres internes?». Acta Geographica. Societé de Géographie, París, nº 79, pp. 20-38.

- (1994): «The creations of regions in Spain and its consequences of urban system and its hierarchy». Aardrijkskundige Studies, Lovaina,1/94, pp. 31-45.

SERRANO J. Mª.; KING, R. (1995): Urban systems and regional organization in Spain. Research Papers in Geography. University of Sussex, Brighton, $61 \mathrm{pp}$.

SERRANO, J.Mª.; CALMÉS, R. (1998): L'Espagne. Du sous-développement au developpement. L'Harmattan, París, 302 pp.

SERRANO, J.M ${ }^{\mathrm{a}}$.; SCHLIEPHAKE, K. (2004): «Spaniens modernes Strassennetz (Autobahnen und Schnellstrassen) und seine Bedeutung für die räumliche Entwicklung». Würzburger Geographische Manuskripte. Heft 67; pp. 111-127; en: K. SCHLIEPHAKE; T. A. SCHENK: Verkehrsgeographie, Mobilität, Logistik und Infrastruktur. Würzburg.

SERRANO, J.M ${ }^{\mathrm{a}}$. (2006): «Aglomeraciones y áreas urbanas en España, dimensión y tendencias. Breves precisiones». Lurralde, Iinvestigación y espacio, Universidad del País Vasco, $\mathrm{n}^{\circ}$ 29, pp. $115-142$.

SORRIBES, J. (1999): Las áreas metropolitanas. Análisis teórico y experiencia comparada. Universidad de Valencia, Valencia, $282 \mathrm{pp}$.

STORPER, M. (2007): «Regional Competitiveness», en: Actas, Congreso Regionales Capitales, Comunidad Autónoma de Madrid, Madrid, pp. 265-287.

UNITED NATIONS (2006): World Urbanization Prospects. The 2005 Revision. Department of Economics and Social affairs. Population Division, Nueva York.

VELTZ, P. (2003): «Villes et mondialisation». L'explosion urbaine. № 81, P.U.F, París, pp. 37-41.

VINUESA, J. (1996): «Dinámica de la población urbana en España, (1857-1991). Ciudad y Territorio. Estudios Territoriales. ${ }^{\circ}$ s 107-8, vol. XXVIII, pp. 105-216.

WRIGHT, A. (1978): The Spanish Economy, 1956-1976). The MacMillan Press, Londres, 195 pp.

ZALDIVAR, C.A.; CASTELlS, M. (1992): España, fin de Siglo, Alianza Editorial, Madrid, 373 pp. 